\title{
Trabalho e formação de professores/as: retrocessos e perdas em tempos de pandemia
}

Work and teacher education:

setbacks and losses in pandemic times

\section{Trabajo y formación de profesores:}

retrocesos y pérdidas en tiempos de pandemia

\section{LUIZ FERNANDES DOURADO*}

Universidade Federal de Goiás, Goiânia-GO, Brasil.

\section{ROMILSON MARTINS SIQUEIRA**}

Pontifícia Universidade Católica de Goiá, Goiânia-GO, Brasil.

\begin{abstract}
RESUMO: Este artigo discute os dados da pesquisa Trabalho docente em tempos de pandemia (Gestrado/UFMG, 2020) e reafirma o movimento de regulação e gerenciamento da formação e atuação dos professores, com ênfase na perda da autonomia e autoria docente e institucional, bem como de um processo de privatização e financeirização com a crise sanitária. Ao mesmo tempo, discorre sobre a formação de professores, ancorada no jogo de forças e interesses divergentes entre duas resoluções (02/2015 e 02/2019). De modo particular, tensiona o lugar das instituições e do professor diante dos processos de implantação da Base Nacional Comum Curricular (BNCC) durante a pandemia.

Palauras-chaves: Formação de professores. Trabalho docente. Pandemia e educação.
\end{abstract}

* Doutor em Educação pela Universidade Federal do Rio de Janeiro. Pós-doutor, em Paris/França, pela École des Hautes Études en Siences Sociales. É professor titular e emérito na Universidade Federal de Goiás e, atualmente, diretor da Anpae. E-mail: <luizdourado1@gmail.com>.

** Doutor e Mestre em Educação pela Universidade Federal de Goiás, mesma instituição na qual atualmente é Pós doutorando. É professor da Pontifícia Universidade Católica de Goiás. Coordena o Grupo de Estudos e Pesquisas sobre Cultura e Educação na Infância. E-mail: <romilsonmartinsiqueira@hotmail.com>. 
ABSTRACT: This article discusses the data from the research Trabalho docente em tempos de pandemia (Gestrado/UFMG, 2020), and reaffirms the movement of regulation and management of teachers' formation and performances, with emphasis on the loss of both teaching and institutional autonomy and authorship, as well as a privatization and financialization process due to the health crisis. At the same time, it discusses teacher education, anchored in the game of forces and divergent interests between two resolutions (02/2015 and 02/2019). In particular, it tensions the place of the institutions and the teachers in the face of the implementation processes of the Base Nacional Comum Curricular (BNCC) during the pandemic.

Keywords: Teacher education. Teaching work. Pandemic and education.

Resumen: Este artículo analiza los datos de la investigación Trabajo docente en tiempos de pandemia (Gestrado/UFMG, 2020) y reafirma el movimiento de regulación y gestión de la formación y desempeño docente, con énfasis en la pérdida de autonomía y autoría docente e institucional, así como un proceso de privatización y financiarización con la crisis sanitaria. Al mismo tiempo, se analiza la formación del profesorado, anclada en el juego de fuerzas e intereses divergentes entre dos resoluciones (02/2015 y 02/2019). En particular, tensa el lugar de las instituciones y del docente ante los procesos de implementación de la Base Curricular Común Nacional (BNCC) durante la pandemia.

Palabras clave: Formación de profesores. Trabajo docente. Pandemia y educación.

\section{Introdução}

“O que dizemos é sempre mais do que o que sabemos acerca do que dizemos. Neste excesso reside o limite da crítica" (SANTOS, 2000, p. 17).

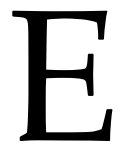

ste trabalho parte de uma tese central: a implementação do ensino remoto no âmbito de um discurso e uma prática gerencialistas ${ }^{1}$ da educação no contexto da pandemia tem naturalizado a Base Nacional Comum Curricular em uma perspectiva reducionista e pragmática, que vai se afirmando pela epistemologia da prática, 
pela teoria das competências, pela padronização curricular e, em muitos casos, pela assimilação de plataformas e dinâmicas que negligenciam o processo pedagógico. Ao mesmo tempo, induz o profissional da educação a uma relação com a tecnologia e suas plataformas como um fim em si mesmo. Esse cenário sinaliza a complexificação das disputas, agora amplamente acentuadas por novas formas de interpenetração das esferas pública e privada, em detrimento do domínio público, da educação pública, de seus estudantes e profissionais. As contradições existem e nos remetem a uma reflexão mais ampla e a embates mais efetivos que resultem no reforço da educação e das escolas públicas, de seu papel político-pedagógico e de novas rotas que possam contribuir com a garantia do direito social para todos, incluindo-se a formação de profissionais da educação e a efetiva criação de uma plataforma pública que envolva as instituições de educação básica e superior.

É nesse contexto que o tema da formação de professores não pode ser desconsiderado, sem a compreensão ampla daquilo que constitui o trabalho e a valorização dos profissionais $^{2}$ da educação: formação inicial e continuada, carreira, salários e condições de trabalho e de saúde (CONAPE, 2018). Os dados da pesquisa realizada pelo Grupo de Estudos sobre Política Educacional e Trabalho Docente da Universidade Federal de Minas Gerais (Gestrado, 2020) permitem apreender dois tipos de projetos formativos distintos em curso. De um lado, um projeto de formação para o qual a naturalização do ensino remoto, como condição sine qua non, não encontra ressonância sem as devidas mediações do trabalho docente em suas condições objetivas, concretas e sociais. De outro, uma lógica de formação praticista, pragmática e adaptativa, que encontra respaldo em um projeto educativo alienado.

Mas o que está em jogo neste campo de disputa? Como expressão do jogo de forças, encontram-se as resoluções CNE CP 02/2015 (BRASIL, 2015) 3 e CNE CP 02/2019 (BRASIL, $2019)^{4}$. A primeira assenta-se no campo dos interesses públicos e na defesa de uma formação docente que compreenda os processos sociais mais amplos e que consiga, nesse contexto, apreender os processos educativos escolares e não escolares. Sem ampla discussão e atrelada à proposição da Base Nacional Comum Curricular (BNCC), encontra-se a segunda Resolução CNE CP 02/2019 (BRASIL, 2019) caracterizada pelas entidades em defesa da educação como retrocesso e descaracterização ${ }^{5}$ da formação de professores.

O contexto da crise pandêmica foi pano de fundo para a implementação da BNCC. Essa ação encontrou, no campo privado, a defesa de um projeto formativo centrado na "epistemologia da prática" e na "pedagogia das competências". Em meio à crise sanitária, pacotes educativos, softwares, plataformas, apostilas, cursos aligeirados, equipamentos, webinars, assessorias e consultorias de empresas, dentre outros, foram contratados/comprados sem considerar o acúmulo e a experiência das universidades e órgãos públicos.

A denúncia da rede Gestrado (2020) sobre como o trabalho e o lugar do professor no contexto da pandemia vêm sendo tratados reafirma um modelo de formação marcado pela 
lógica pragmática: aprende o conteúdo, aprende fazendo, aprende praticando, aprende em serviço, aprende a aplicar o conteúdo e avalia o que aplicou. Essa lógica está ancorada em dois pressupostos: o primeiro, a emergência de uma racionalização técnica e de administração social em diferentes setores sociais (POPKEWITZ, 1997); o segundo, a adoção de um discurso de afirmação da incompetência do professor, portanto da necessidade de se criarem modelos de formação e aprendizagem docentes. Assim,

a racionalização é uma tecnologia do poder no sentido produtivo. A racionalização é uma técnica de administração social. A preocupação é a de racionalizar o pensamento dos professores com um molde regulador. [...] Os professores individuais são monitorados através de avaliações externas e através das distinções aplicadas para a determinação das suas competências pessoais. A finalidade dos sistemas reguladores é a de orientar o indivíduo na determinação de necessidades, satisfação e maior conhecimento. Os professores são encorajados ‘a monitorar seu próprio pensamento'. Tornando publicamente disponível o pensamento privado, a psicologia do raciocínio torna os professores individuais mais abertos à inspeção e à regulação (POPKEWITZ, 1997, p. 198).

A racionalização técnica está evidente nos dados apreendidos pela pesquisa da rede Gestrado (2020): a instrumentalização dos meios, dos recursos, dos conteúdos, da lógica do processo de ensino-aprendizagem, da tecnologia, do tempo, do conhecimento e do saber-fazer docente. $\mathrm{O}$ trabalho do professor também é recobrado no contexto da pandemia. Há, nesse cenário, um discurso da incompetência, do fracasso, da individualização e, paradoxalmente, da responsabilização do professor. Portanto, o ataque continuado aos professores, parcialmente justificado pelo domínio e pela atuação, faz compreender que

a individualização tem um enfoque especial. Não é o de entender o pensamento, as ações e as práticas da pessoa sozinha. Ela define as pessoas como parte de uma população agregada e atribui categorias ao pensamento como um método de monitoramento dos indivíduos. A individualização ocorre através da aplicação de modelos de raciocínio para a supervisão e avaliação do trabalho específico de um professor (POPKEWITZ, 1997, p. 198).

Ao tratar da intensificação, precarização e instrumentalização do trabalho dos professores, a rede Gestrado (2020) sinaliza o predomínio de uma lógica que recoloca a raiz dos problemas educacionais nos sujeitos e desconsidera as condições sociais, históricas e concretas em que a educação se efetiva. É justamente a compreensão restrita da educação que tem gerado discursos e práticas tão aderentes a projetos de professores tão aligeirados, praticistas e descolados das universidades como locus da formação, conforme também expressa Hypolito (2019). Em contraposição, a rede Gestrado (2020) reafirma a importância de o tema ser tratado com base em uma concepção de sistema nacional de educação, na necessária articulação entre os entes federados, seus órgãos, instituições, bem como na autonomia dos profissionais e dos estudantes como sujeitos do processo. 
Um dos aspectos evidenciados pela pesquisa da rede Gestrado (2020) é a padronização curricular e o controle do ato de ensinar sobre os professores. Se tomarmos aquilo que o Movimento "Todos pela Base" defende e explicita em seus documentos, ou seja, “a BNCC não determina como ensinar, mas 'o que ensinar' [...]." (grifo nosso) ${ }^{6}$, é possível, então, afirmar que a pandemia e a BNCC reconfiguraram o lugar do professor. Nesse contexto, o papel e o lugar do professor como um intelectual tornam-se irrelevantes, uma vez que sua autonomia é reduzida e controlada. Para Tumolo e Fontana:

a padronização dos programas de ensino e dos currículos escolares contribuiu para uma diminuição na participação do professor no resultado do seu trabalho, já que estas regulamentações influenciam no conteúdo que o professor deve ensinar e em como ele irá ensinar (2008, p. 164).

Está se falando de processos de cerceamento da autonomia docente no que diz respeito ao processo formativo de ensino não só em relação à definição dos conteúdos curriculares, mas também, e principalmente, nas dinâmicas curriculares por ele desenvolvidas. Assim,

considerando a parceria nefasta das políticas de testagem externa com a Base Nacional Comum Curricular e seu estreito vínculo com competências e capacidades supostamente necessárias, os modos e as tentativas incessantes de conceber a qualidade da educação têm agido de maneira sutil e perniciosa, "coisificando os conhecimentos, ferindo a autonomia, desumanizando o trabalho docente e, ainda, descaracterizando o estudante na sua condição de diferente, de outro legítimo" (SÜSSEKIND; MASKE, 2020, p. 181).

\section{Padronização, instrumentalização e implementação da BNCC}

A discussão deste artigo pauta-se na crítica contundente à proposição, à regulação e ao alinhamento da BNCC-BNC Formação-Ensino Remoto. Se, por um lado, a Resolução CNE CP 02/2019 encontrou ressonância em um projeto de governo e em segmentos da sociedade civil aliados ao setor privado, por outro, o contexto de pandemia vivido em 2020 em função do novo coronavírus e da Covid 19 acelerou os processos de implementação aligeirada da Base e de seus desdobramentos político-pedagógicos. A necessidade de distanciamento social e o cumprimento de protocolos de saúde pública redefiniram os cenários até então vividos no mundo. Isso implicou lockdown em inúmeras cidades, instalação do home office, suspensão imediata das aulas, adoção do ensino remoto com estratégias síncronas e assíncronas, dentre outras ações. No campo da educação, registra-se a ausência do Ministério da Educação na proposição de um plano estratégico de enfrentamento da crise, bem como no efetivo apoio aos entes federados. O CNE optou por pareceres, com discussão restrita, em detrimento de diretrizes nacionais construídas com ampla participação. Essa opção corroborou o eixo da flexibilização dos dias letivos e legitimou a adoção de estratégias não presenciais, deixando a cargo dos demais entes 
federados e conselhos a definição de políticas e parâmetros, cuja condução de ações foi, muitas vezes, conflitante e sem o efetivo acompanhamento e financiamento.

De pronto, os professores tiveram que, além de dominar novas estratégias de ensino e novas tecnologias, fazer uso também de um currículo que se forjou "necessário" devido ao contexto pandêmico. Trata-se aqui de grades curriculares com videoaulas veiculadas por meio de rádio e $\mathrm{TV}$, com horários rígidos, softwares e plataformas com conteúdos produzidos por equipes técnicas da secretaria, responsáveis pela produção, reprodução e distribuição de material impresso e padronizado, dentre outras estratégias.

A fim de compreender os cenários nos quais os professores vivenciaram tais contextos, a Gestrado/UFMG realizou a pesquisa Trabalho Docente em Tempos de Pandemia ${ }^{7}$, coordenado pela profa. dra. Dalila Andrade de Oliveira, que contou com a parceria da Confederação Nacional dos Trabalhadores em Educação (CNTE) para a mobilização dos respondentes e a divulgação dos resultados. A amostra da pesquisa foi constituída por 15.654 professores(as) das redes públicas da educação básica ${ }^{8}$. Importante é destacar a abrangência da pesquisa e da amostra realizada e a riqueza dos indicadores produzidos. A pesquisa constata questões de grande relevância, a saber, as que se listam a seguir.

\section{A mulher e o trabalho remoto}

Dos informantes da pesquisa, 78\% são mulheres. Esse dado é relevante, se tomarmos em conta que o excesso de trabalho decorrente dessa nova configuração do ensino também se depara com a dura jornada feminina de trabalho (em casa e em outros espaços). Soma-se a esse dado aquele que indica que $84 \%$ do total dos respondentes continuaram suas atividades em trabalho remoto. Uma nova configuração do trabalho, agora improvisada e compartilhada em um mesmo ambiente doméstico, passou a marcar o cotidiano dos(as) profissionais da educação.

\section{O despreparo das redes na condução de políticas educacionais em períodos emergenciais}

A pesquisa contribuiu para compreender a complexa situação docente, agravada no contexto da pandemia. Chama a atenção o fato de as redes de ensino não estarem preparadas para a adoção de estratégias, como o ensino remoto, para a implementação de plataformas de ensino com conteúdos e videoaulas, bem como para a utilização de recursos tecnológicos e redes sociais. Mais grave ainda é a ausência de uma política sistêmica nas Redes para lidar com situações de resolução de crises.

\section{Condições objetivas, ações propostas e seus descompassos}


Quanto a esse descompasso entre as condições objetivas dos profissionais e as ações propostas, a pesquisa sinaliza que,

embora exista distanciamento social em função da Covid-19, a grande parte (84\%) dos(as) professores(as) continua a desenvolver atividades de trabalho de forma remota. A suspensão das atividades escolares atingiu com maior intensidade os(as) professores(as) das Redes de Ensino Municipais. Isso comparado aos das Redes de Ensino Estaduais (GESTRADO, 2020, p. 10).

Da mesma forma,

embora 15,8\% dos(as) professores(as) respondentes da pesquisa não estivessem realizando atividades escolares não presenciais, eles foram avaliados quanto ao preparo para a realização dessa forma de ensino e à disponibilidade de recursos tecnológicos para tal. Apesar de as atividades escolares terem sido suspensas, quase a metade $(46 \%)$ desses docentes continua interagindo com os estudantes (GESTRADO, 2020, p. 11).

Os dados permitem, à primeira vista, indicar que os professores estão envolvidos nas atividades remotas; todavia, há a necessidade de definir aquilo que as nomeia como "atividades de trabalho de forma remota". O que se quer tensionar aqui é o fato de que o trabalho docente, em seu sentido mais amplo, pode estar subsumido na categoria atividade de trabalho, esta última marcada por estratégias pontuais e de forma naturalizada. O mesmo pode ser considerado quanto àquilo que se nomeia "interação com o estudante". Pelos dados, mais de $54 \%$ dos estudantes encontram-se à margem do ensino remoto. Desses, os(as) professores(as) indicam que, para 46,1\%, a participação dos alunos reduziu um pouco com o ensino remoto. Já para 37,7\% desses(as) profissionais, a participação dos alunos reduziu drasticamente. A pesquisa ainda ressalta que 1 a cada 3 estudantes não tem acesso aos recursos tecnológicos para acompanhar as aulas remotas. Aos que estão inclusos, questiona-se: qual a qualidade dessas interações? Elas garantem, de fato, aprendizagens? E aos que não estão fora dessa margem, quem lhes assegura o direito à educação?

Sobre a formação e o domínio para ministrar o ensino remoto, a pesquisa mostra que, "embora possuam recursos tecnológicos, mais da metade (53,6\%) não possui preparo para ministrar aulas não presenciais" (GESTRADO, 2020, p. 12). Observamos nos dados a denúncia dos professores sobre a precariedade do ensino oferecido, em uma ação que desconsidera a formação como condição para o domínio do processo e exercício profissional.

Da mesma forma, a pesquisa indica que, "caso precisassem realizar atividade de ensino a distância, apenas 3 a cada 10 professores(as) da Educação Básica possuem tanto recursos tecnológicos quanto preparo necessário à realização das atividades" (GESTRADO, 2020, p. 12). Outrossim, 41,5\% compartilham seus recursos tecnológicos com outros membros da família. Esse dado demonstra que as condições objetivas e as 
condições de trabalho docente devem ser consideradas no campo da proposição e materialização de políticas na educação.

Esse processo de atividades não presenciais, sobretudo, remotas, efetivou-se em detrimento da educação a distância como modalidade e sem as condições objetivas para a garantia de processos formativos com qualidade e sem garantia de acessibilidade para todos os estudantes e profissionais. Por outro lado, a adoção de "pacotes" tecnológicos veio acompanhada de uma política desordenada de aplicação e naturalização da BNCC de forma muito mais homogeneizada e padronizadora, o que poderá resultar em processo de ampla privatização e perda de autonomia docente.

\section{Intensificação, massificação e padronização pedagógica}

Uma das questões mais preocupantes apontadas pela pesquisa da Gestrado (2020) diz respeito ao trabalho dos professores da educação infantil. Segundo consta, "em relação aos profissionais que desenvolvem trabalho à distância: 1 a cada 17 profissionais da Educação Infantil realizam esse trabalho na própria escola" (GESTRADO, 2020, p. 14).

Os(as) profissionais da educação infantil informaram à pesquisa que 36, 7\% das crianças não têm acesso ao ensino remoto; $34,6 \%$ das crianças não têm autonomia para acompanharem e desenvolverem as atividades sozinhas; e 36,0\% dos pais não conseguem fazer a mediação da aprendizagem por meio do ensino remoto. Esses dados se somam àqueles em que o trabalho na educação infantil ocorre em $13,4 \%$ por meio de atividades remotas e a maioria, 56,1\%, por meio de vídeos gravados pelos(as) profissionais. Esses resultados nos permitem questionar: que lugar tem ocupado a educação infantil no contexto da pandemia? Que direitos estão sendo negados às crianças? Que lugar têm ocupado seus profissionais?

Se comparado ao trabalho de professores em outras etapas ou modalidades, a pesquisa mostra que a educação infantil não tem sido objeto de preocupação das redes no processo de ensino remoto:

os formatos de aula remota disponibilizados aos estudantes diferenciam entre as
etapas/subetapas da Educação Básica. Os professores(as) da Educação Infantil foram
os que mais realizaram a gravação de videoaulas, tendo sido produzidas por mais
da metade dos participantes. $33,5 \%$ dos professores(as) do Ensino Médio realiza-
vam aulas remotas ao vivo (GESTRADO, 2020, p. 15).

Observamos, nos dados, que os profissionais da educação infantil tiveram suas jornadas de trabalho ampliadas no home office e voltadas, quase que exclusivamente, para a gravação de vídeos. O trabalho docente em home office passa a conviver com rotinas exaustivas de trabalho doméstico e cuidados com a família em contextos de distanciamento social. Ressaltamos, ainda, que a instrumentalização do trabalho e das relações humanas, tão necessárias na educação infantil, acaba por formalizar-se em vídeoaulas, para as 
quais esses docentes não foram preparados para sua produção: “à medida que se avança nas etapas/subetapas da Educação Básica, aumenta a cobertura de suporte oferecido aos docentes. Assim, a pior situação refere-se à Educação Infantil, em que 15\% não possuem suporte, e a melhor, no Ensino Médio (9\%)" (GESTRADO, 2020, p. 17).

Outros dados desta pesquisa corroboram as críticas aqui acentuadas:

9 a cada 10 professores(as) utilizam o telefone celular na realização das aulas a distância. Em seguida, aparece o notebook, sendo usado por 76,0\% dos participantes. Dois (2) a cada 3 participantes possuíam internet banda larga. Outros $24,0 \%$ utilizavam dados do plano de celular para ministrarem as aulas remotas (GESTRADO, 2020, p. 15).

\section{As notas conclusivas da pesquisa indicam que}

os docentes foram convocados, na maioria dos casos, a realizarem seu trabalho de outra maneira, em outros contextos, inclusive virtual, adaptando suas atividades, desenvolvendo habilidades para lidar com novas ferramentas e metodologias para responder a essa situação inteiramente inusitada. Essas adaptações exigiram esforços que não podem ser desprezados. A maioria desses profissionais não recebeu qualquer formação para o desenvolvimento dessas atividades. Entretanto, percebe-se que o compromisso desses professores(as) com seus estudantes tem orientado a busca de meios para tornar a oferta educativa possível. Essa experiência pode significar um importante crescimento e amadurecimento profissional, mas ela também é geradora de tensões e angústias para os docentes (GESTRADO, 2020, p. 21).

Os recortes apresentados da pesquisa possibilitam reafirmar cenários de desigualdades no campo da formação docente, mas, acima de tudo, no uso das tecnologias de forma acrítica e pragmática. As universidades não foram mobilizadas para contribuir com o processo de formação dos docentes para uso tão abrupto desses recursos. A utilização em massa não implica necessariamente uma expansão qualitativa no ensino e

o que está em jogo é o modo como a contradição expansão-redução tem sido 'resolvida' em termos de política educacional: ao invés de fortalecer as instâncias universitárias de formação docente pela incorporação das TIC, esta promove um modelo de substituição tecnológica (BARRETO, 2008, p. 922).

Da mesma forma, o ensino remoto foi tomado, em muitos casos, como modalidade de educação a distância (EaD), ainda que flexibilizado em sua dimensão regulatória e pedagógica. Importante é ressaltar a secundarização dos marcos regulatórios e a validação de todas as atividades não presenciais efetivadas para poucos e com acessibilidade bastante limitada, em muitos casos, reduzida a tarefas escolares.

Nessa esteira,

sem negar o acesso aos diferentes produtos do trabalho humano, as TIC obviamente incluídas, como condição necessária a qualquer proposta democrática, é preciso reconhecer que o acesso em si não é suficiente. A apropriação, como horizonte, requer o reconhecimento de fronteira mais complexa, colocando de um lado 
os que podem até mesmo modificar as aplicações da tecnologia e, de outro, os consumidores de pacotes, limitados a operações tão simples quanto previsíveis. Em se tratando da recontextualização educacional das TIC, este reconhecimento remete à superação de condições restritivas, unidirecionais, como o lugar de usuário que recebe, em 'pacotes tecnológicos', informações pré-selecionadas a serem apreendidas, retidas e (com)provadas (BARRETO, 2008, p. 931).

Outros dois estudos sobre a educação em contextos de pandemia podem contribuir para as reflexões apresentadas pela rede Gestrado (2020). Apesar de serem produzidas por outros interlocutores, há em comum entre esses estudos a necessidade de uma reflexão sobre todo o processo vivido em tempos de pandemia. O Relatório Brasil (2020), Desafios das Secretarias Municipais de Educação na oferta de atividades educacionais não presenciais, é fruto de uma pesquisa ${ }^{9}$ realizada pela União Nacional dos Dirigentes Municipais de Educação (Undime), Conselho Nacional de Secretários de Educação (Consed) e apoio do Centro de Inovação para a Educação Brasileira (CIEB), Fundação Itaú de Educação e Cultura e outros parceiros do terceiro setor. Os dados apontam indicadores extremamente complexos e preocupantes e corroboram os achados da pesquisa mencionada, conforme se registram a seguir:

1. sobre as condições objetivas dos estudantes: " $83 \%$ dos alunos das redes públicas do Brasil vivem em famílias vulneráveis (que recebem até 1 salário mínimo per capita)" (RELATÓRIO BRASIL, 2020, p. 8);

2. o acesso à internet é, sobretudo via celular, limitado aos conteúdos online: “79\% dos alunos das redes públicas do Brasil tem acesso à internet, mas $46 \%$ acessam apenas por celular" (RELATÓRIO BRASIL, 2020, p. 9);

3. Em face da determinação sanitária, a pesquisa constatou que " $60 \%$ das redes municipais brasileiras determinaram suspensão das aulas com atividades remotas" (RELATÓRIO BRASIL, 2020, p. 10) e que " 1.710 redes municipais (43\% das que adotam ensino remoto) tem optado por usar materiais impressos como parte das estratégias" e "materiais impressos, videoaulas e conteúdos digitais são as principais estratégias." (RELATÓRIO BRASIL, 2020, p. 12);

4. o monitoramento das atividades remotas é muito baixo, pois somente "958 redes municipais (53,4\% das que adotam ensino remoto) tem políticas de rede para monitorar as atividades remotas" (RELATÓRIO BRASIL, 2020, p.17);

5. “Das 1.578 redes municipais que não têm planos para atividades remotas, $90 \%$ são de municípios pequenos", o que sinaliza para desigualdades técnicas, pedagógicas e financeiras entre os municípios. Assim, "é importante destacar 66 municípios de maior porte que também não se estruturaram" (RELATÓRIO BRASIL, 2020, p. 25). 
Os dados dessa pesquisa reafirmam a naturalização da exclusão dos estudantes, pois "a maior parte das redes ainda não tem planos para ensino remoto atenderem alunos mais carentes" (RELATÓRIO BRASIL, 2020, p. 26).

Já o Relatório Sentimento e percepção dos professores brasileiros nos diferentes estágios do coronavírus no Brasil estágio intermediário - maio de 2020, realizado pelo Instituto Península (2020), demostra que, no contexto da pandemia, os professores têm se sentido ansiosos (67\%), entediados (36\%), cansados (38\%), estressados (34\%), sobrecarregados (35\%), frustrados (27\%). São indicadores que demonstram as complexas situações em que se encontram esses profissionais, submetidos, em muitos casos, a processos de intensificação e precarização das condições de trabalho.

A pesquisa constata, ainda, que as principais mudanças identificadas pelos profissionais nesse processo foram que,

\begin{abstract}
na pesquisa inicial, $75 \%$ dos professores já indicavam ter mudado muito ou totalmente seus hábitos. Já na 2ª pesquisa, esse percentual subiu para 79\%. Os professores indicam que estão dedicando menos tempo ao lazer e mais tempo aos estudos. Atualmente, 3 em cada 4 professores acreditam que o papel do professor é interagir remotamente com os alunos. No início da paralisação, essa relação era de 2 para cada 5 professores (INSTITUTO PENÍNSULA, 2020).
\end{abstract}

Uma análise pormenorizada dos dados precisa ser feita, mas, em uma análise preliminar, já é possível identificar o nível de assimilação e naturalização das atividades de interação remota e a intensificação do trabalho como inexoráveis .

As três pesquisas em pauta possibilitam depreender que os encaminhamentos tomados, sem diálogo com a categoria ou articulação sistêmica, fizeram com que se agravasse ainda mais o quadro da desigualdade educacional no País; exacerbaram e naturalizaram processos de exclusão social/digital em níveis sem precedentes; expuseram os professores a novas rotinas para as quais não foram preparados e a que tiveram de se submeter, em muitos casos, sem garantia de processos formativos; e naturalizaram as novas tecnologias no campo da atuação profissional. Tal processo teve desdobramentos complexos também em relação aos estudantes e suas famílias, incluindo-se as questões de acessibilidade, a adequação aos novos formatos e às demandas pedagógicas, que, quando efetivadas, ocorreram, em boa parte dos casos, sem a garantia de condições objetivas e o devido acompanhamento e apoio pedagógico, a despeito do compromisso do professor e da intensificação e precarização do trabalho vivenciado.

\title{
Perspectivas para o trabalho docente pós-pandemia
}

Os dados do relatório de pesquisa da rede Gestrado (2020) diferenciam-se dos das demais, justamente, por nos possibilitarem profundas reflexões sobre a formação e o trabalho docente. Que projeto(s) formativo(s) as IES e universidades estão construindo? Que 
tipo de formação, para qual sociedade? O que sabemos sobre os professores e sua atuação profissional em tempos de pandemia? Como romper com modelos e práticas tão aderentes ao campo da formação docente? Essas e tantas outras questões indicam a necessidade de uma formação crítica, capaz de tomar o trabalho docente como objeto de estudo das políticas educacionais.

Aquilo que se vivencia na proposição e materialização da BNCC no campo da formação de professores, em pleno contexto de pandemia, traduz-se em um movimento de regulação que fere a autonomia das IES e a autoria intelectual dos professores. Isso porque a centralidade da formação não pode recair no domínio de conteúdo-competência-habilidades. Contrapor essa visão reducionista nos remete, ainda, à defesa da articulação entre formação inicial e continuada; à efetiva institucionalização de projetos institucionais nas IES, construídos coletivamente com as instituições de educação básica e que garantam sólida formação teórica e interdisciplinar em educação; à unidade entre teoria e prática; à centralidade do trabalho como princípio educativo; à pesquisa como princípio cognitivo e formativo e, portanto, ao eixo nucleador da formação.

Assim,

à BNCC não cabe fixar mínimos curriculares nacionais ou engessar a ação pedagógica com objetivos de aprendizagem dissociados do desenvolvimento integral do estudante que limitam o direito a educação e, ao mesmo tempo, a aprendizagem. É importante considerar, como eixo fundamental de uma proposta de direitos e objetivos de aprendizagem e desenvolvimento, a garantia dos princípios constitucionais de liberdade de aprender, ensinar, pesquisar e divulgar o pensamento, a arte e o saber, bem como o pluralismo de ideias e de concepções pedagógicas (AGUIAR; DOURADO, 2019, p. 19).

É preciso, portanto, defender um amplo movimento que tensione os limites da base: a base curricular (BNCC) e a base sobre as quais se assentam a implementação do ensino remoto e a utilização acrítica das tecnologias de informação e comunicação (TIC) em tempos de pandemia. Esse movimento deve retomar o sentido da concepção de base comum nacional, na qual a Política de Formação de Professores (definida no Decreto MEC n. 8.752/2016 e nos princípios da Resolução CNE CP 2/2015) se expresse e se materialize nos projetos institucionais das IES em efetiva articulação com as instituições de educação básica.

Retirar dos profissionais da educação a tarefa de pensar a relação sociedade-educação-conhecimento e converter sua formação ao domínio de conteúdos definidos a partir de uma base nacional comum curricular é empobrecer o papel das universidades e do sentido de uma identidade/formação comprometida com um projeto de nação socialmente mais justo e democrático.

A pandemia e a implementação do ensino remoto não podem converter-se em modelo para a implementação de uma política de educação que se efetiva na improvisação, na 
adaptação, na tecnificação, na padronização e na lógica da exclusão. A questão do direito à educação, bem como ao conhecimento como um bem público e social, não pode converter-se em moeda de troca em uma sociedade que não reconhece o trabalho docente como trabalho intelectual e as universidades como espaços emancipatórios de formação.

A naturalização de uma lógica política marcada pela ausência de diretrizes nacionais para a educação e de efetivo apoio técnico e financeiro por parte do governo federal, indutoras da flexibilização dos dias letivos e da adoção das atividades não presenciais, foi o caminho fértil para avanços nos processos de clara interpenetração da esfera pública na esfera privada, em detrimento da esfera pública, envolvendo diversos atores institucionais ou não ligados ao setor privado e à financeirização. Não se trata de acidente de percurso, mas de intensificação de uma política de desmonte do setor público, de apropriação e controle dos processos e dinâmicas pedagógicas em detrimento da autonomia das instituições e de seus profissionais. Reafirma-se, aqui, a necessidade de se atentar para as condições objetivas de vida e trabalho dos professores, intensificadas pela pandemia e agravadas pelas dificuldades de organização, gestão e acompanhamento das atividades pelas redes de ensino, pelas condições de trabalho a que os professores foram submetidos, pelo acesso excludente da maioria dos estudantes. Nesse cenário, as lutas em prol da retomada do Estado no financiamento das políticas públicas, especialmente da educação pública, gratuita, laica, democrática, inclusiva e de qualidade, se fazem necessárias. De igual modo, é fundamental garantir a valorização dos profissionais da educação (formação inicial e continuada, carreira, salários e condições de trabalho e saúde); as condições de acesso e permanência dos estudantes com direito à educação de qualidade, o que inclui dinâmicas pedagógicas adequadas e com efetivo acompanhamento e condições de acessibilidade para todos.

Nessa direção, reafirma-se o Manifesto dos Educadores e Educadoras, Estudantes, Brasileiros e Brasileiras em defesa da democracia, da vida, dos direitos sociais e da Educação, aprovado pelo Fórum Nacional Popular de Educação (2020), que nos alerta:

\footnotetext{
Não é aceitável que, em um contexto de aguda crise sanitária, permitamos a consolidação de monopólios de oferta de plataformas, tecnologias e conteúdos que terão uma consequência aguda sobre a educação, fragilizando, ainda mais, os princípios do pluralismo de ideias e de concepções pedagógicas e a própria liberdade de aprender, ensinar, pesquisar e divulgar o pensamento e o saber. Precisamos objetar, como vigor, as tentativas de substituição da escola presencial e a centralidade do professor por arremedos de aulas remotas ou mesmo a EAD, que deve ser, sempre, devidamente regulada e controlada pelo poder público.
}

Um outro caminho que precisa ser fortemente considerado por nossas instituições é a construção de uma Plataforma Pública que pode ser viabilizada por consórcio de universidades e instituições de educação básica públicas, entidades acadêmicas, sindicais e estudantis, mobilizados para apoiar os projetos pedagógicos e formativos, a ação docente 
e as práticas pedagógicas mediadas por tecnologias educacionais, públicas, de acesso livre e gratuitas (MANIFESTO FNPE, 2020). Como espaços públicos, essas plataformas poderão contribuir para a produção e socialização de conhecimentos socialmente significativos e apoiar coletivamente o trabalho dos professores nas instituições educacionais, nas redes e nos ambientes virtuais de aprendizagens. Este deve ser um compromisso e uma agenda social no campo das políticas públicas de educação para além dos períodos cíclicos de crises.

Recebido em: 23/10/2020 e Aprovado em: 12/11/2020

\section{Notas}

1 O modelo de gerencialismo está centrado em "parcerias público-privadas, com a terceirização da produção de materiais didáticos e venda de sistemas apostilados, com a inclusão de sistemas de gestão educacional, na forma de aplicativos ou plataformas digitais, que monitoram todo o sistema administrativo e pedagógico, retira das escolas e do professorado o controle sobre o que deve ser ensinado e como deve ser ensinado" (HYPOLITO, 2019, p. 194).

2 Uma concepção ampliada de valorização dos profissionais da Educação pode ser apreendida dos debates e documentos inerentes à Conferência Nacional de Educação (Conae/2014) e Conferência Nacional Popular de Educação (2018).

3 Resolução CNE/CP n. 2, de 1ํo de julho de 2015, que define as Diretrizes Curriculares Nacionais para a formação inicial em nível superior (cursos de licenciatura, cursos de formação pedagógica para graduados e cursos de segunda licenciatura). O perfil de professor defendido, em seu Art. 5º, que define que "a formação de profissionais do magistério deve assegurar a 'base comum nacional', pautada pela concepção de educação como processo emancipatório e permanente, bem como pelo 'reconhecimento da especificidade do trabalho docente', que conduz à práxis como expressão da articulação entre teoria e prática e à exigência de que se leve em conta a realidade dos ambientes das instituições educativas da educação básica e da profissão (BRASIL, 2015).

4 Também conhecida como BNC Formação, trata-se da Resolução CNE/CP n. 2, de 20 de dezembro de 2019. Define as Diretrizes Curriculares Nacionais para a Formação Inicial de Professores para a Educação Básica e institui a Base Nacional Comum para a Formação Inicial de Professores da Educação Básica.

5 Ver “Nota das entidades nacionais em defesa da Resolução 02/2015” (ANFOPE, 2019).

6 Disponível em:<http://movimentopelabase.org.br/>. Acesso em: nov. 2020.

7 OGESTRADO/UFMG é responsável pelo desenho metodológico da pesquisa, construção do instrumento de coleta de dados, além da sistematização e análise dos resultados. Nesta investigação, o público-alvo contempla os(as) professores(as) da Educação Básica das redes públicas estaduais e municipais. Conforme dados do Censo Escolar da Educação Básica de 2019, esse universo abrange cerca de 1,7 milhões de profissionais. A coleta de dados ocorreu por meio de questionário online autoaplicado, disponibilizado na plataforma Google Forms. Os dados foram coletados no período de 8 a 30 de junho de 2020.

8 "A amostra da pesquisa foi constituída por 15.654 professores(as) das redes públicas da Educação Básica. Isso após analisar o banco de dados e eliminar os questionários com preenchimento incompleto e os casos duplicados. Sobre os tópicos pesquisados, as questões foram distribuídas em quatro blocos: 1. Perfil dos(as) respondentes; 2. Utilização de tecnologias digitais; 3. Docentes com aulas suspensas; e 4. Desenvolvimento de atividades escolares remotas" (Gestrado, 2020). 
9 Relatório Brasil (2020, p. 6): “Desafios das Secretarias Municipais de Educação na oferta de atividades educacionais não presenciais". Abrangência da pesquisa: 3.978 redes municipais responderam à pesquisa $(71 \%$ do total): “Em número de matrículas a pesquisa representa 14,4 milhões de alunos (70\% do total de matrículas das redes municipais do Brasil)".

\section{Referências}

AGUIAR, Márcia Ângela da S.; DOURADO, Luiz Fernandes. BNCC e formação de professores: concepções, tensões, atores e estratégias. Revista Retratos da Escola, Brasília, CNTE, v.13, n. 25, p. 33-37, jan./ maio 2019.

ANFOPE et al. Contra a descaracterização da Formação de Professores. Nota das entidades nacionais em defesa da Resolução 02 /2015. 2019. Disponível em: http://costalima.ufrrj.br/index.php/FORMOV/article/ view/538/836. Acesso em: 11/11/2020.

BARRETO. Raquel Goulart. As tecnologias na política nacional de formação de professores a distância: entre a expansão e a redução. Educação e Sociedade, Campinas, v. 29, n. 104 - Especial, p. 919-937, out. 2008.

BRASIL. Lei n. 13.005, de 25 de junho de 2014. Aprova o Plano Nacional de Educação PNE e dá outras providências. Diário Oficial da União, Brasília, DF, 2014.

BRASIL. Resolução CNE/CP n. 2, de $1^{\circ}$ de julho de 2015, que define as Diretrizes Curriculares Nacionais para a formação inicial em nível superior (cursos de licenciatura, cursos de formação pedagógica para graduados e cursos de segunda licenciatura). Diário Oficial da União, Brasília, DF, 2015.

BRASIL. Decreto $n^{\underline{0}}$ 8.752, de 9 de maio de 2016. Dispõe sobre a Política Nacional de Formação dos Profissionais da Educação Básica.

BRASIL. Resolução CNE/CP n. 2, de 20 de dezembro de 2019. Define as Diretrizes Curriculares Nacionais para a Formação Inicial de Professores para a Educação Básica e institui a Base Nacional Comum para a Formação Inicial de Professores da Educação Básica. Diário Oficial da União, Brasília, DF, 2019.

CONEPE. Conferência Nacional de Educação Fórum Nacional Popular de Educação. 2018. Disponível em http://fnpe.com.br/docs/documentos/docs -conferencia/proposta_documento base_plano_de_ lutas final apreciacao_pleno-22-05-2018.pdf Acesso 11/11/2020

DOURADO, Luiz Fernandes. Valorização dos profissionais da educação Desafios para garantir conquistas da democracia. Revista Retratos da Escola, Brasília, v. 10, n. 18, p. 37-56, jan./jun. 2016.

A formação de professores e a base comum nacional: questões e proposições para o debate. In: ROCHA, D; VEIGA, I. P., MACHADO, L.C. Formação de professores: currículo, saberes e práticas pedagógicas, Curitiba: CRV, 2019. p. 319- 338.

FÓRUM NACIONAL POPULAR DE EDUCAÇÃO. Manifesto em defesa da educação como Direito Público. 2020. Disponível em: https://fnpe.com.br/manifesto-em-defesa-da-educacao-como-direitopublico/.

GESTRADO/UFMG; OLIVEIRA, Dalila Andrade (Org.). Trabalho docente em tempos de pandemia. Relatório Técnico. Belo Horizonte, 2020.

HYPOLITO, Álvaro Moreira. BNCC, Agenda Global e Formação Docente. Revista Retratos da Escola, Brasília, v. 13, n. 25, p. 187-201, jan./maio 2019. 
INSTITUTO PENÍNSULA. Sentimento e percepção dos professores brasileiros nos diferentes estágios do coronavírus no Brasil estágio intermediário. Relatório de maio de 2020.

POPKEWITZ, Thomas S. Reforma Educacional: por uma leitura sociológica - Poder e conhecimento em Educação. Tradução de Beatriz Affonso Neves. Porto Alegre: Artes Médicas, 1997.

SANTOS, Boaventura de Sousa. Crítica da razão indolente: contra o desperdício de experiência. São Paulo: Cortez, 2000.

SÜSSEKIND, Maria Luiza; MASKE, Jeferson. "Pendurando roupas nos varais": Base Nacional Comum Curricular, trabalho docente e qualidade. Em Aberto, Brasília, v. 33, n. 107, p. 173-187, jan./abr., 2020.

TUMOLO, Paulo Sergio; FONTANA, Klalter Bez. Trabalho docente e capitalismo: um estudo crítico da produção acadêmica da década de 1990. Educação e Sociedade, Campinas, v. 29, n. 102, 159-180, jan./ abr., 2008. 